\title{
Assess the Knowledge Regarding Jejunostomy Feeding Among Staff Nurses and Nursing Students in NMCH, Nellore
}

Authors

\author{
Mrs. Kanaka Lakshmi.R ${ }^{1}$, Mrs. Indira.S ${ }^{2}$, Ms Betty lebona ${ }^{3}$, Ms Sarada.K ${ }^{4}$
}

${ }^{1}$ Assistant Professor, Dept of Medical, Surgical Nursing, Narayana College of Nursing, Chinthareddypalem ${ }^{2}$ Principal, Narayana College of Nursing

${ }^{3,4}$ Assistant Professor

\begin{abstract}
Jejunostomy feeding is defined as a tube surgically or endoscopically inserted through the abdomen and into the jejunum. Jejunostomy feeding is indicated for the patient who needs long term entered nutrition. If cannot feed himself by mouth and needs building up, an alternative to total parental nutrition is to put in a tube into the jejunum and feed through that. Feeding jejunostomy are seldom needed, but they can be life saving for examples when a suture line in an injured duodenum need protecting. To reduce the danger of a leak, introduce the tube into gut through a long oblique track.
\end{abstract}

METHODOLOGY: Quantitative research approach was utilized to assess the knowledge regarding jejunostomy feeding among the staff Nurses and nursing students in NMCH, Nellore. The sample size was 60 ,of the 30 were staff nurses and 30 were student nurses. Non-probability convenience sampling technique was used for selection. of subjects. Semi structured questionnaire was used to assess the knowledge of staff nurses and student nurses regarding Jejunostomy feeding.

RESULTS: Level of knowledge regarding jejunostomy feeding among staff nurses, 3(20\%) had inadequate knowledge, 8(53.3\%) had moderately adequate knowledge and 4(26.7\%) had adequate knowledge. Shows that with regard to knowledge regarding jejunostomy feeding among nursing students, 6(40\%) had inadequate knowledge, 4 (26.7\%) had moderate knowledge and 5(33.3\%) had adequate knowledge.

CONCLUSION: The study concluded that majority of staff nurses had moderately adequate knowledge when compare to nursing students.

\section{INTRODUCTION}

It is a tube surgically or endoscopically inserted through the abdomen and into the jejunum. Jejunostomy feeding indications are, an esophageal obstruction which is correctable, to protect a suture line in the duodenum following an injury, to protect an suture line in the stomach which has leaked, a pancreatic abscess. The main importance of jeunostomy feeding which will the advantage of early central feeding the jejunostomy may lead to serious complication which lot of morbidity. jejunostomy feeding is an aseptic non touch techniques procedure as it is important to be aware of any medication that the taking which could affect the $\mathrm{PH}$ of the gastric aspirate, in the jejunostomy feeding the importance is more 
comfort is than safety. Its important of specifically the complication of jejunostomy feeding. Jejunostomy feeding play an important roles in providing nutrition and maintaining of gut structure and function. Jejunostomy feeding can be made be an open method, percutaneous method or laproendoscopic method.

\section{ELAHEH ASHOURI AND NAHIDEH}

FATEHI (2010) conducted a study on descriptive-analytic cross-sectional study on 37 nurses who worked in the general surgery and neurology wards and fed patients suffering from gastrostomy. A valid and reliable checklist was used for data collection. To analyze the data, the descriptive statistical method (frequency and mean) and inferential method (paired t-test, Spearman Correlation Coefficient and variance Analysis with repetition of observations) were used. The findings showed that the mean score of measures in all the stages (before, during, and after administration) was significantly lower than the standard $(\mathrm{p}<0.001)$. There was a significant reverse relation between the score of measures in all the three stages (before, during, and after administration), and work record and work experience in the ward.

\section{STATEMENT OF THE PROBLEM}

A STUDY TO ASSESS THE KNOWLEDGE REGARDING JEJUNOSTOMY FEEDING AMONG STAFF NURSES AND NURSING STUDENTS IN NMCH, NELLORE.

\section{OBJECTIVES}

1. To assess the level of knowledge regarding jejunostomy feeding among staff nurse in $\mathrm{NMCH}$,Nellore.

2. To assess the level of knowledge regarding jejunostomy feeding among nursing student in $\mathrm{NMCH}$, Nellore

3. To compare the level of knowledge regarding jejunstomy feeding between staff nurses and nursing students in $\mathrm{NMCH}$, Nellore.
4. To associate the level of knowledge regarding jejunostomy feeding among staff nurses with their selected socio demographic variables.

5. To associate the level of knowledge regarding jejunostomy feeding among nursing students with their selected socio demographic variables.

\section{ASSUMPTIONS}

The staff nurse and nursing students have some knowledge regarding jejunostomy feeding.

\section{MATERIALS AND METHODS}

Quantitative research approach was utilized to assess the knowledge regarding jejunostomy feeding among the staff Nurses and nursing students in $\mathrm{NMCH}$, Nellore. The sample size was 60 ,of the 30 were staff nurses and 30 were student nurses. Non-probability convenience sampling technique was used for selection. of subjects. Semi structured questionnaire was used to assess the knowledge of staff nurses and student nurses regarding Jejunostomy feeding.

\section{CRITERIA FOR SAMPLE SELECTION INCLUSION CRITERIA}

1. Staff nurses who are available at the time of data collection

2. Nurses who know well English

3. Student nurses who are available at the time of data collection

\section{EXCLUSION CRITERIA:}

1. Nurses who are excluded based on the following criteria

2. Nurses who are not willing to participate in this study

3. Nurses who are on leave

\section{DESCRIPTION OF THE TOOL}

The tool consists of two parts. 


\section{PART-I.}

\section{Deal with demographic data}

Demographic variables including Age, education, occupation, income, place of residence, religion, type of family, sources of information, habits

\section{PART II.}

Deals with knowledge questionnaire to assess the knowledge regarding jejunostomy feeding.

\section{SCORE INTERPRETATION}

\begin{tabular}{|l|l|c|c|}
\hline S.NO & $\begin{array}{l}\text { LEVEL OF } \\
\text { KNOWLEDGE }\end{array}$ & SCORE & PERCENTAGE \\
\hline $\mathbf{1 .}$ & $\begin{array}{l}\text { Inadequate } \\
\text { knowledge }\end{array}$ & $\mathbf{1 - 1 0}$ & $<\mathbf{5 0}$ \\
\hline $\mathbf{2 .}$ & $\begin{array}{l}\text { Moderately } \\
\text { adequate knowledge }\end{array}$ & $\mathbf{1 1 - 2 0}$ & $\mathbf{5 1 - 7 0}$ \\
\hline $\mathbf{3 .}$ & $\begin{array}{l}\text { Adequate } \\
\text { knowledge }\end{array}$ & $\mathbf{2 1 - 3 0}$ & $>\mathbf{7 1}$ \\
\hline
\end{tabular}

\section{DATA COLLECTION PROCEDURE}

The data collection procedure was done for a period of 1 week from $5 / 5 / 15$ to $10 / 5 / 15$. After obtaining the formal permission from the Narayana College of nursing. 30 samples were selected by non probability convenience sampling techniques. Nursing students and staff nurses, who fulfilled the inclusion criteria, were included for this study after obtaining informed consent from them and the confidentiality of shared was assured. For the present study knowledge questionnaire based interview method was adopted to collect the data, it took 30 minutes to complete the questionnaire for staff nurses and nursing student.

\section{PLAN FOR DATA ANALYSIS}

Data analysis was done using descriptive statistics and inferential statistics.

\section{Descriptive statistics:}

$>$ frequency and percentage distribution of demographic variables

Mean \& standard deviation

\section{Inferential statistics}

$>$ chi-square test to find association with knowledge of mothers .

\section{RESULTS}

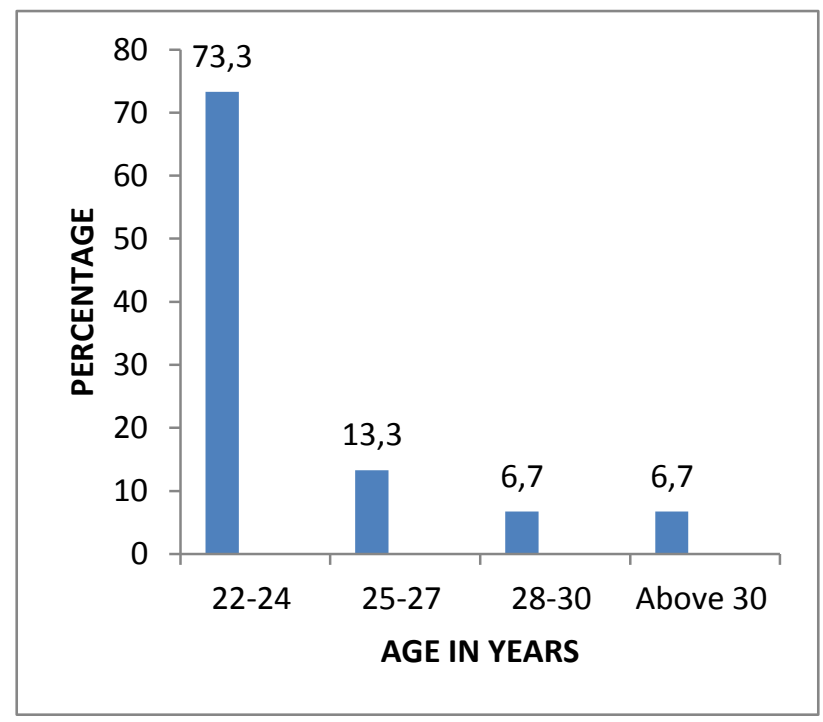

Fig No.1 Percentage distribution of staff nurse based on age.

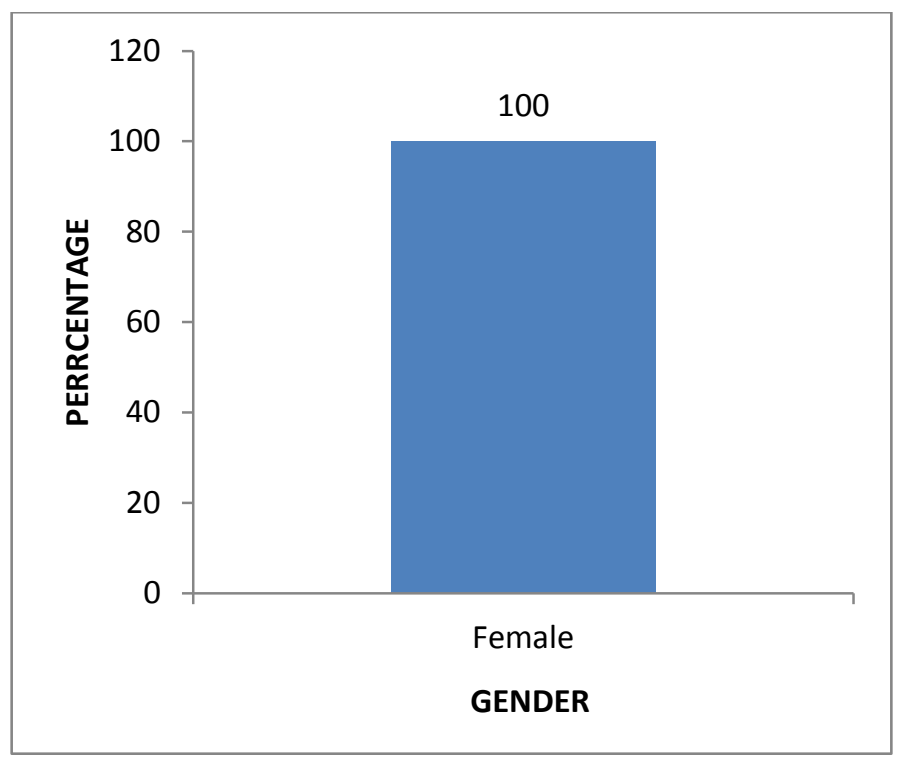

Fig No-2 Percentage distribution of staff nurse based on gender. 


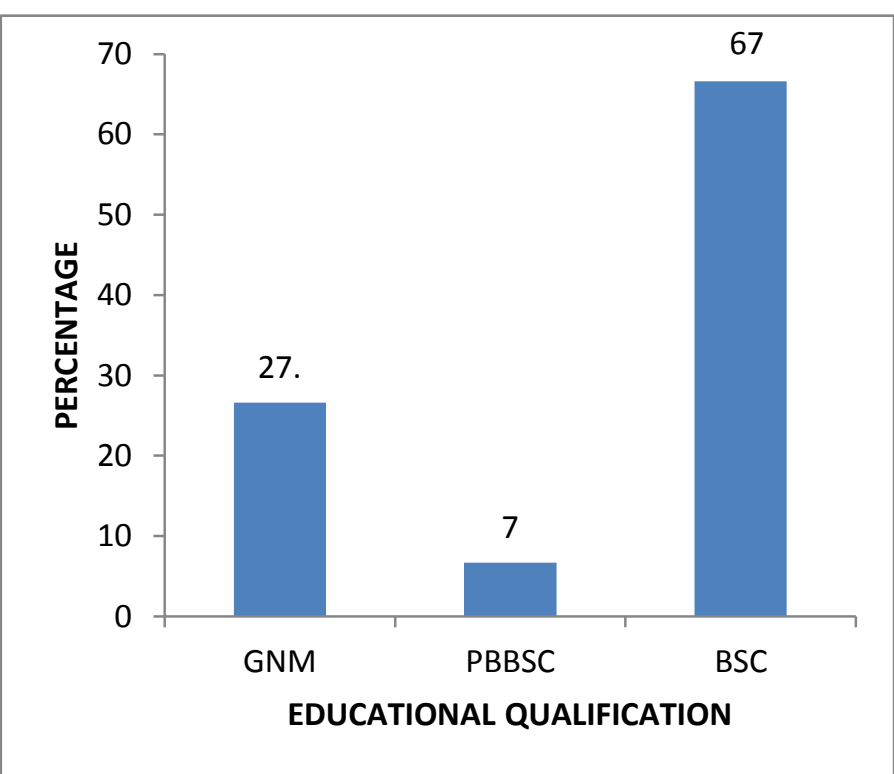

Fig No.3 Percentage distribution of staff nurses based on Educational qualification.

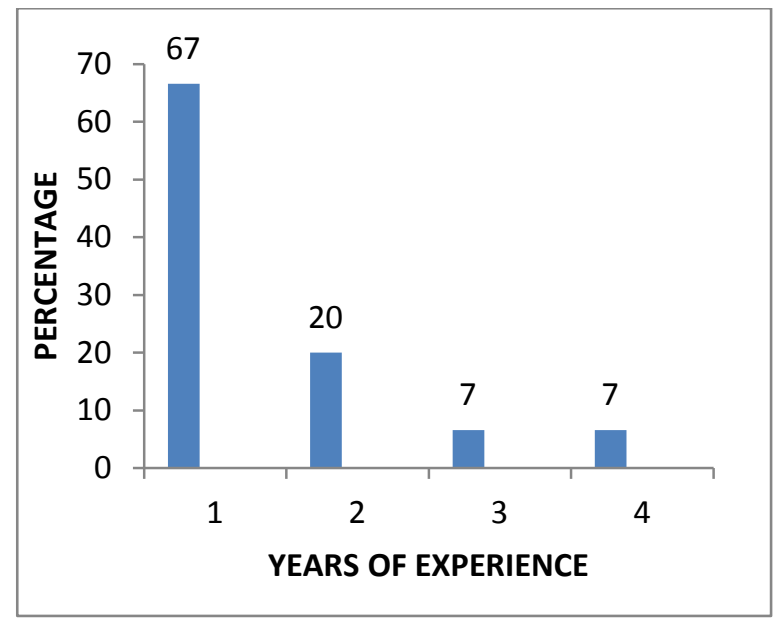

Fig: 4 Percentage distributions of staff nurses based on Years of experiences.

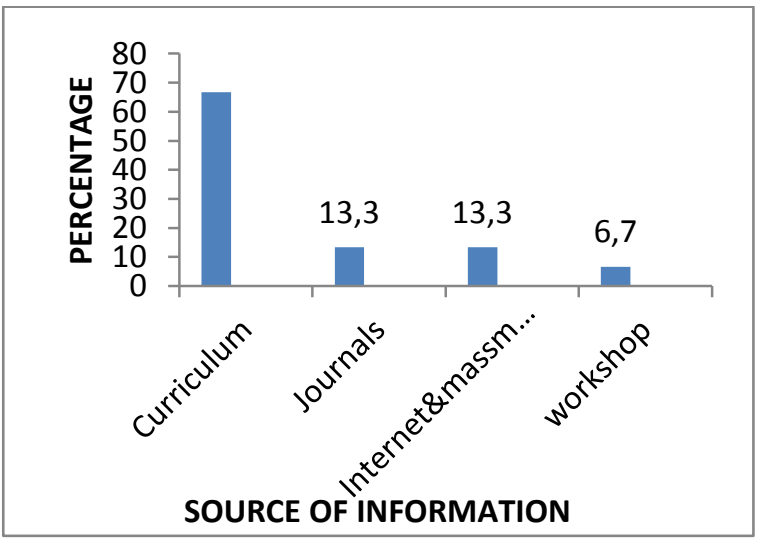

Fig: 5 Percentage distributions of staff nurses based on Source of information.

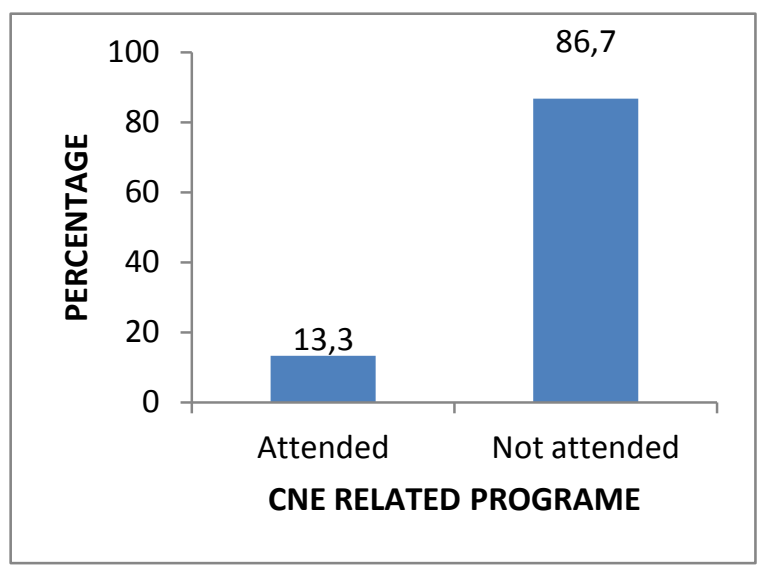

Fig 6: Percentage distribution of staff nurses who attended CNE related Jejunostomy feeding.

Frequency and percentage distribution of demographic variables of nursing students.

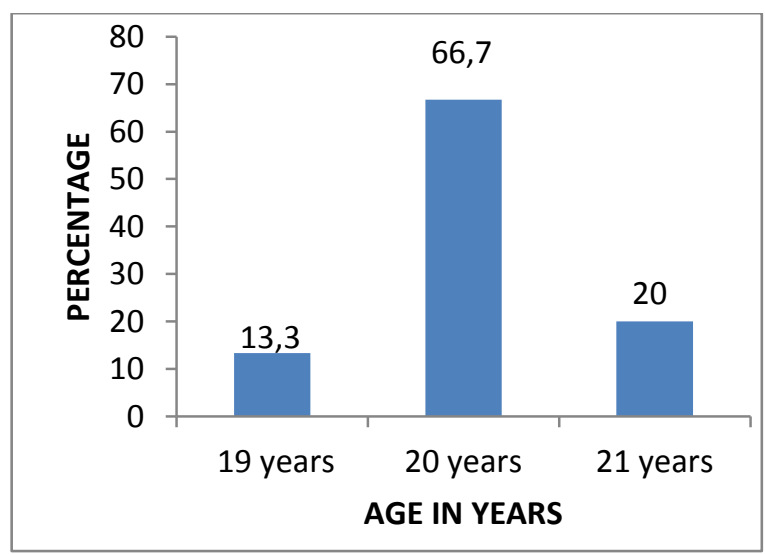

Fig-7. Percentage distribution of nursing students based on Age.

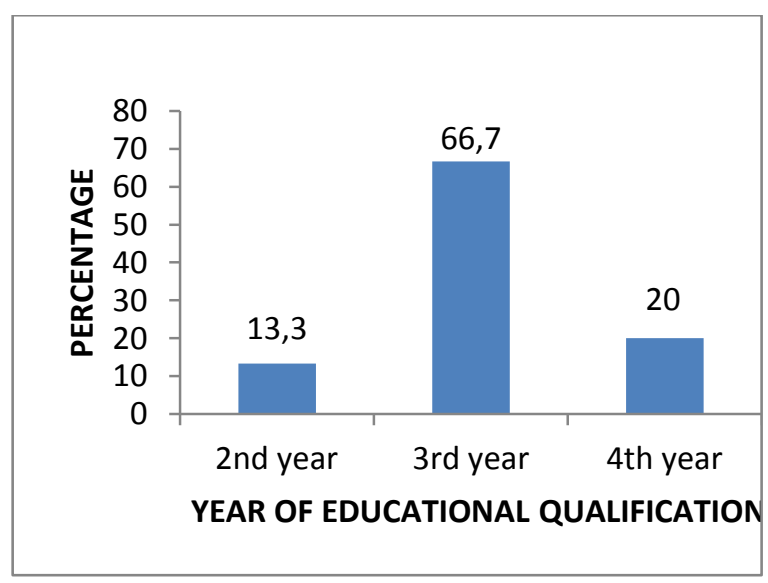

Fig-8 Percentage distribution of nursing students based on year of educational qualification. 


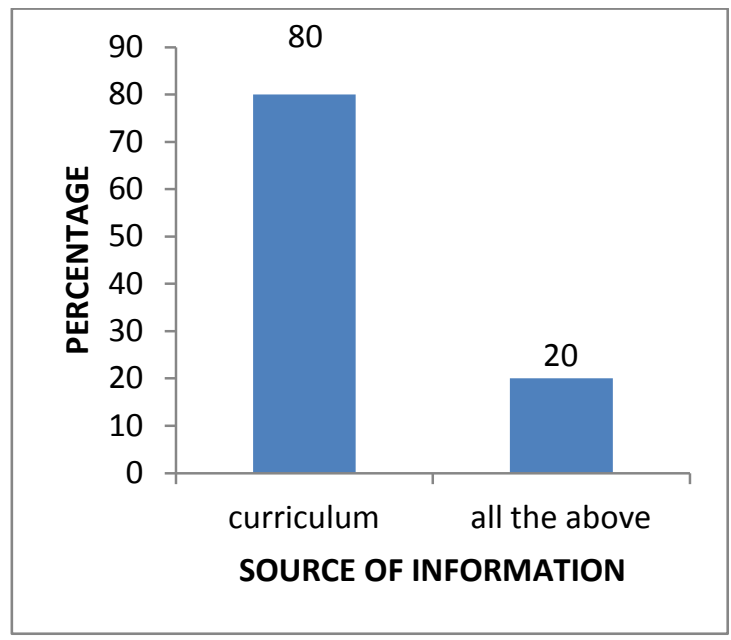

Fig-9 Percentage distribution of nursing students based on source of information.

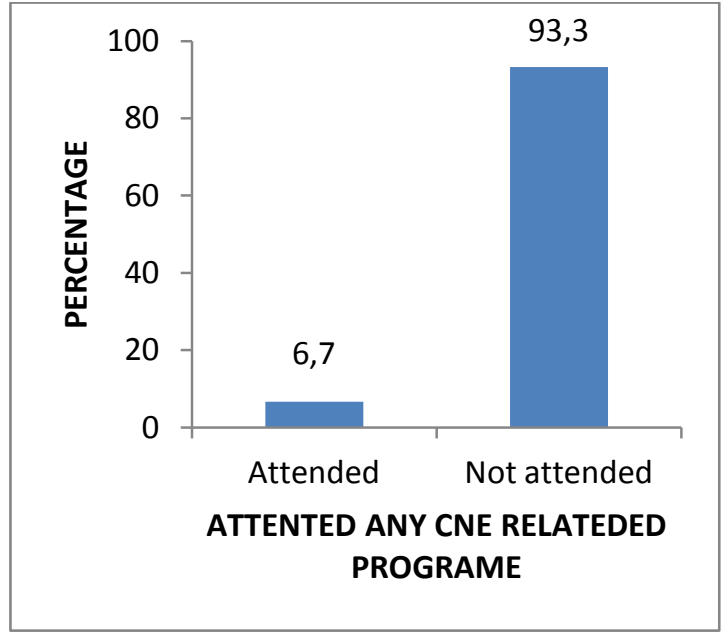

Fig-10 Percentage distribution of nursing students based on attended CNE program.

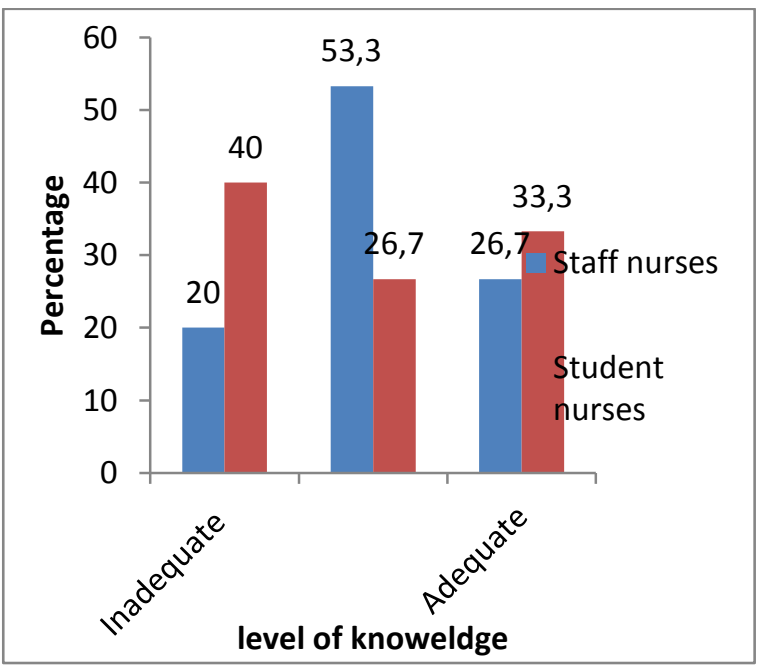

Fig-11 Comparison of level of knowledge regarding jejunostomy feeding between staff nurses and nursing students.

\section{SECTION-III}

Table: 1 Comparison of mean knowledge score and standard deviation between staff nurses and nursing students.

\begin{tabular}{|l|l|c|l|l|l|}
\hline Group & Mean & $\begin{array}{l}\text { Standard } \\
\text { Deviation }\end{array}$ & & & \\
\hline Staff nurses & 18.53 & 3.61 & & & \\
\hline $\begin{array}{l}\text { Nursing } \\
\text { students }\end{array}$ & 17.2 & 4.88 & & & \\
\hline
\end{tabular}

SECTION- Table-11 Association of level of knowledge regarding Jejunostomy feeding among staff nurses with their selected socio-demographic variables.

\begin{tabular}{|c|c|c|c|c|c|c|c|c|}
\hline S.No & $\begin{array}{l}\text { Demographic } \\
\text { variables }\end{array}$ & & & & & & $\begin{array}{l}\text { quate } \\
\text { edge }\end{array}$ & Chi-square \\
\hline & & $\mathrm{f}$ & $\%$ & $\mathrm{f}$ & $\%$ & $\mathrm{f}$ & $\%$ & \\
\hline 1. & $\begin{array}{l}\text { Age } \\
\text { a) } 22-24 \mathrm{yrs} \\
\text { b) } 25-27 \mathrm{yrs} \\
\text { c) } 28-30 \mathrm{yrs} \\
\text { d)Above } 30 \mathrm{yrs}\end{array}$ & $\begin{array}{l}1 \\
2 \\
1\end{array}$ & $\begin{array}{l}6.7 \\
13.3 \\
6.7 \\
-\end{array}$ & - & $\begin{array}{l}53.3 \\
- \\
- \\
-\end{array}$ & 2 & $\begin{array}{l}13.3 \\
- \\
- \\
6.7\end{array}$ & $\begin{array}{l}C=13.24 \\
t=12.592 \\
d f=6 \\
S^{*} \\
P=0.05\end{array}$ \\
\hline 2. & $\begin{array}{l}\text { Do you attended } \\
\text { any CNE related } \\
\text { to jejunostomy } \\
\text { feeding } \\
\text { a. yes } \\
\text { b. no }\end{array}$ & 4 & $\begin{array}{l}- \\
26.7\end{array}$ & 8 & $\begin{array}{l}- \\
53.3\end{array}$ & 1 & $\begin{array}{l}13.3 \\
6.7\end{array}$ & $\begin{array}{l}c=9.22 \\
t=9.12 \\
d f=.2 \\
S * *\end{array}$ \\
\hline
\end{tabular}

Description of demographic variables of staff nurses:- Shows that with regard to age of staff nurses, 11(73.3\%) are between 22-24years, with regard to gender all the, $15(100 \%)$ are females nurses, with regard to educational qualification of staff nurses, 10(66.6\%) studied BSc (n), with regard to year of experience, $10(66.6 \%)$ had 1 year ,with regard to source of information 10(66.7\%) received from curriculum, with regard to attended CNE programme13 (86.7\%) have not attended the CNE program.

Description of demographic variables of nursing students.

with regard to age, $10(66.7 \%)$ are 20 years,with regard to educational status of the nursing students, $10(66.7 \%)$ are studying 3rd year BSC 
nursing, with regard to source of information, $12(80 \%)$ received from curriculum, with regard to attended workshop, 14(93\%) have not attended .

\section{FINDINGS OF THE STUDY BASED ON OBJECTIVES}

The level of knowledge regarding jejunostomy feeding among staff nurse.

FIG 11: Shows that with regard to level of knowledge regarding jejunostomy feeding among staff nurses, 3(20\%) had inadequate knowledge, $8(53.3 \%)$ had moderately adequate knowledge and $4(26.7 \%)$ had adequate knowledge.

Jain A Agawam Ret.al (2010) Findings of this study was consistent with a study conducted by to assess the knowledge regarding feeding jejunostomy among 50 staff nurses in a New Delhi, India using a randomized controlled trail. The study result shows that the mean application score is 8.3 higher in staff nurses. The study concluded the staff nurses had adequate knowledge regarding jejunostomy feeding.

The level of knowledge regarding jejunostomy feeding among nursing students in NMCH, Nellore.

Shows that with regard to knowledge regarding jejunostomy feeding among nursing students, $6(40 \%)$ had inadequate knowledge, $4(26.7 \%)$ had moderate knowledge and 5(33.3\%) had adequate knowledge.

LEOPOUL J K (2008) Finding of this study was consistent with a study conducted by to assess the level of knowledge regarding jejunostomy feeding among 115 nursing students in Portugal using a randomized trial. Students were randomly assigned in to two groups the first $(n=21)$ participated in a $30 \mathrm{~min}$ supervised self study session while the second $(n=24)$ attended $30 \mathrm{~min}$ feeding jejunostomy session. The study results shows that pretest and post test scores were similar in both groups $(\mathrm{P}=0.118$ and $\mathrm{P}=0.263$, respectively). The study concluded that the student nurses had inadequate knowledge regarding jejunostomy feeding.
Comparison of the level of knowledge of staff nurses and nursing students regarding jejunostomy feeding

shows that with regard to comparison of level of knowledge regarding jejunostomy feeding between staff nurses and nursing students, 3 (20\%)of staff nurses are having inadequate knowledge, $8(53 \%)$ are having moderate knowledge, 4 (27\%) are having adequate knowledge. Among nursing students have 6(40\%) are having in adequate knowledge, 4(27\%) are have moderate knowledge and 5(33\%) are have adequate knowledge, In staff nurses, the mean score is 18.53 with standard deviation of 3.61 where as in nursing students, the mean score is 17.2with standared deviation of 4.88 .

Fujimoto Francis (2012) Findigs of this study was consistent with a study conducyed by to assess the level of knowledge regarding jejunostomy feeding among 66 staff nurses and 53 student nurses in hospital settings of Ameria. The study result shows that the mean score of staff nurses is $\mathrm{x}=6.45$ and student nurses mean is $x=4.01$. The staff nurses had adequate knowledge than student nurses. The study concluded that the jejunostomy feeding knowledge of staff nurses are sufficient and the student nurses are not sufficient, indicating the necessity of feeding education for student nurses.

The association between the level of knowledge of staff nurses regarding jejunostomy feeding and selected socio demographic variables.

Shows that there is a significant association between the level of knowledge regarding jejunostomy feeding among staff nurses with their selected socio demographic variables like Age in years, Educational qualification, year of experience, Source of information and Attended any CNE programme.

J C MONTEJO (2011) Findings of this study consistent with a study conducted by to assess the level of knowledge regarding jejunostomy feeding procedure in the hospital at panchmabal district among 50 staff nurses. The study result shows that mean point is increased from $\mathrm{x}=2.33$ to $\mathrm{x}=8.77$ 
and knowledge gain as 7.56 and mean point of staff nurses is significance association between their selected socio demographic variables like age, gender, source of information, years of experience.

The association between the level of knowledge of nursing students regarding jejunostomy feeding and selected socio demographic variables.

Table no:- 15 Shows that there is no significant association between the level of knowledge regarding jejunostomy feeding among nursing students with their selected socio demographic variables like Age in years, Years of course and Source of information and attended any CNE programmed. MINNESOTA (2010) Finding of this study consistent with a study conducted by to assess the level of knowledge regarding feeding jejunostomy in Udaipur city among 120 BSc (n) students. The study result shows that the maximum respondents $50(40.8 \%)$ are in the age group 20-21 years. The mean point is increased from $x=1.50$ to $x=7.00$ and knowledge gain as 5.08 and mean point of student nurses is not significance association between their selected socio demographic variables like age, gender, source of information, years of course.

\section{REFERENCE}

1. ANNABELLA .M.KEENE,"clinical nursing and related science", 6th edition.

2. BRUNNER AND SUDDARTH text book of "Medical surgical nursing", $10^{\text {th }}$ edition, published by Suzanne smelter Brendage Bare.

3. BT BASVANTHAPPA text books of "medical surgical nursing", $1^{\text {st }}$ edition, published by Jaypee.

4. JOYEE M BLACK "Medical surgical nursing", $6^{\text {th }}$ edition volume-1, WB sounder company.

5. LEWIS "Medical surgical nursing" WB sounder company.

6. LEMONE BURKE (1996) "Text book of Medical and Surgical Nursing-Critical thinking in client care". New York, $4^{\text {th }}$ edition, Addison Wesley publication.

7. LUCK MAN'S CORE "Principals and practice of medical surgical nursing “, WB sounder company.

8. PHIPPS "Medical surgical nursing health and illness", perspectives $8^{\text {th }}$ edition; Moshy publications.

9. RICK DANIELES (1998) "Contemporary medical and surgical nursing”. Wesley publication, $2^{\text {nd }}$ edition.

10. SHAFER'S “Medical surgical nursing", $7^{\text {th }}$ edition, Phipps publishers. 